STUDI

FRANCESI

\section{Studi Francesi}

Rivista quadrimestrale fondata da Franco Simone

185 (LXII | II) | 2018

OCTAVE MIRBEAU: UNE CONSCIENCE AU TOURNANT

DU SIEECLE - sous la direction de Ida Merello

\title{
MICHEL JOURDE, Jacques Peletier et Louise Labé: à propos de quelques hypothèses récentes
}

\section{Filippo Fassina}

\section{(2) OpenEdition \\ Journals}

Édition électronique

URL : http://journals.openedition.org/studifrancesi/13481

DOI : 10.4000/studifrancesi. 13481

ISSN : 2421-5856

Éditeur

Rosenberg \& Sellier

\section{Édition imprimée}

Date de publication : 1 août 2018

Pagination : 312

ISSN : 0039-2944

\section{Référence électronique}

Filippo Fassina, « MICHEL JouRdE, Jacques Peletier et Louise Labé: à propos de quelques hypothèses récentes », Studi Francesi [En ligne], 185 (LXII | II) | 2018, mis en ligne le 01 août 2018, consulté le 13 janvier 2021. URL : http://journals.openedition.org/studifrancesi/13481 ; DOI : https://doi.org/ 10.4000/studifrancesi.13481

Ce document a été généré automatiquement le 13 janvier 2021.

\section{(c)}

Studi Francesi è distribuita con Licenza Creative Commons Attribuzione - Non commerciale - Non opere derivate 4.0 Internazionale. 


\title{
MICHEL JOURDE, Jacques Peletier et Louise Labé: à propos de quelques hypothèses récentes
}

\author{
Filippo Fassina
}

\section{RÉFÉRENCE}

MICHEL JOURDE, Jacques Peletier et Louise Labé: à propos de quelques hypothèses récentes, «Bibliothèque d'Humanisme et Renaissance» 2, LXXIX (2017), pp. 299-311.

1 La teoria di Mireille Huchon, secondo la quale le Euvres de Louize Labé Lionnoize sarebbero un'opera mistificatrice, senza alcun rapporto con l'esistenza effettiva della poetessa lionese, è qui analizzata in relazione al ruolo che Jacques Peletier avrebbe avuto nell'elaborazione di questo testo e nella creazione del mito letterario della poetessa Louise. Nel 1555 infatti viene pubblicata un'ode "À Louise Labé Lionnoese», contenuta all'interno dell'Art poétique, ma del tutto assente nelle Euvres. Secondo Mireille Huchon, tale assenza è motivata dal fatto che Peletier, dopo aver collaborato inizialmente al progetto di creazione del personaggio di Labé, avrebbe successivamente rifiutato questo progetto di falsificazione. La pubblicazione dell'ode all'interno dell'Art poétique, secondo Huchon, sarebbe in realtà dovuta all'intervento dell'editore Jean de Tournes, che, avrebbe riunito vari testi di circostanza per promuovere l'opera di Louise Labé. Sulla base di queste considerazioni, l'A. ripercorre i punti fondamentali della teoria proposta da Huchon, con la finalità di confutare l'idea secondo la quale Jacques Peletier avrebbe rotto il legame di amicizia con gli altri ideatori della finzione. Le prove di Mireille Huchon si basano fondamentalmente sull'analisi di tre testi, nei quali si troverebbero tracce di questa amitié blessée: una lettera di Peletier «A Toumas Corbin Bourdeloes», il Dialogue de l'ortografe e un'altra lettera inviata a Maurice Scève. Tuttavia, nessuno degli elementi che sostengono la teoria in questione, secondo l'A., va oltre una semplice interpretazione personale di elementi lessicali o contestuali, mentre l'unico 
fatto accertato resta la pubblicazione da parte di Peletier di un'ode a Louise Labé, senza che di questa si possa in alcun modo fornire una lettura ironica o parodica. 